\title{
ANATOMIC VARIATION OF TYPE III RIGHT TESTICULAR VENOUS DRAINAGE: A CASE REPORT
}

\author{
Eren Ogut ${ }^{1}$, Cagatay Barut ${ }^{1}$
}

${ }^{1}$ Bahcesehir University, School of Medicine, Department of Anatomy, Istanbul, Turkey

Corresponding Author: Cagatay Barut, MD, PhD, E-mail: cagbarut@yahoo.com.tr

Received: 01.05.2021; Accepted: 18.01.2022; Available Online Date: 27.01.2022

(C) Copyright 2021 by Dokuz Eylül University, Institute of Health Sciences - Available online at https://dergipark.org.tr/en/pub/jbachs

Cite this article as: Ogut E, Barut C. Anatomic Variation of Type III Right Testicular Venous Drainage: A Case Report. J Basic Clin Health Sci 2022; 6: 314-317.

\begin{abstract}
The testicular vein exhibits variations in number, course, and insertion. Such differences may enhance the risk of varicocele and complication in patients by impairing testicular drainage. The following is a case report of the abnormal drainage of the right testicular vein (RTV) draining into the right renal vein (RRV). The incidence, course, insertion, and termination angle of the testicular veins were measured with a 150 $\mathrm{mm}$ digital Vernier dial microcaliper, and photographs were taken by Canon EOS 70D using a 100mm macro lens. In one out of seven cadavers (14.28\%), the right testicular vein (RTV) drained into the right renal vein (RRV) (Type III) rather than into the inferior vena cava (IVC) at a $90^{\circ}$ angle $0.4 \mathrm{~cm}$ from the IVC. The double (medial and lateral) left testicular veins (LTV) drained into the left renal vein (LRV) at a $62^{\circ}$ angle $5 \mathrm{~cm}$ from the IVC. The understanding of type III RTV drainage or course can provide crucial data for surgeons in order to prevent complications during right-sided varicocele surgery.
\end{abstract}

Keywords: Testicular vein, variation, varicocele, venous drainage, venous variation.

\section{INTRODUCTION}

The network of veins emerging from the testis and epididymis unite to form the pampiniform venous plexus and ascend in the spermatic cord. The veins of each pampiniform plexus meet superiorly, forming a right testicular vein (RTV), which drains to the inferior vena cava (IVC), and a left testicular vein (LTV), which drains to the left renal vein (LRV) (1). However, abnormal drainage patterns of the testicular veins can occur in patients, and such anatomical variations provoke relatively weak hemodynamics in the testicular veins and can lead to varicocele (2). Varicocele commonly occurs on the left side because the acute angle at which the RTV drains to the IVC is more favorable to flow than the nearly $90^{\circ}$ angle at which the LTV drains to the left renal vein, making it more vulnerable to obstruction or reversal of flow (1).
Although there have been a considerable number of case reports on a variation of RTV drainage, little attention has been given to the classification of this variation. We summarize here the fixed cadaver of a 62 years old man with a RTV variation. The following is a case report of the abnormal drainage of the RTV draining into the RRV.

\section{CASE REPORT}

The present study was conducted at the Department of Anatomy, Bahçeşehir University, Istanbul, Turkey. During routine dissection, abnormal insertion of the right testicular vein was identified. The posterior abdominal wall and components were dissected to reveal the testicular vessels (2). The RTV variations were recorded and photographs were taken as defined by Barut and Ertilav (3). The types of 

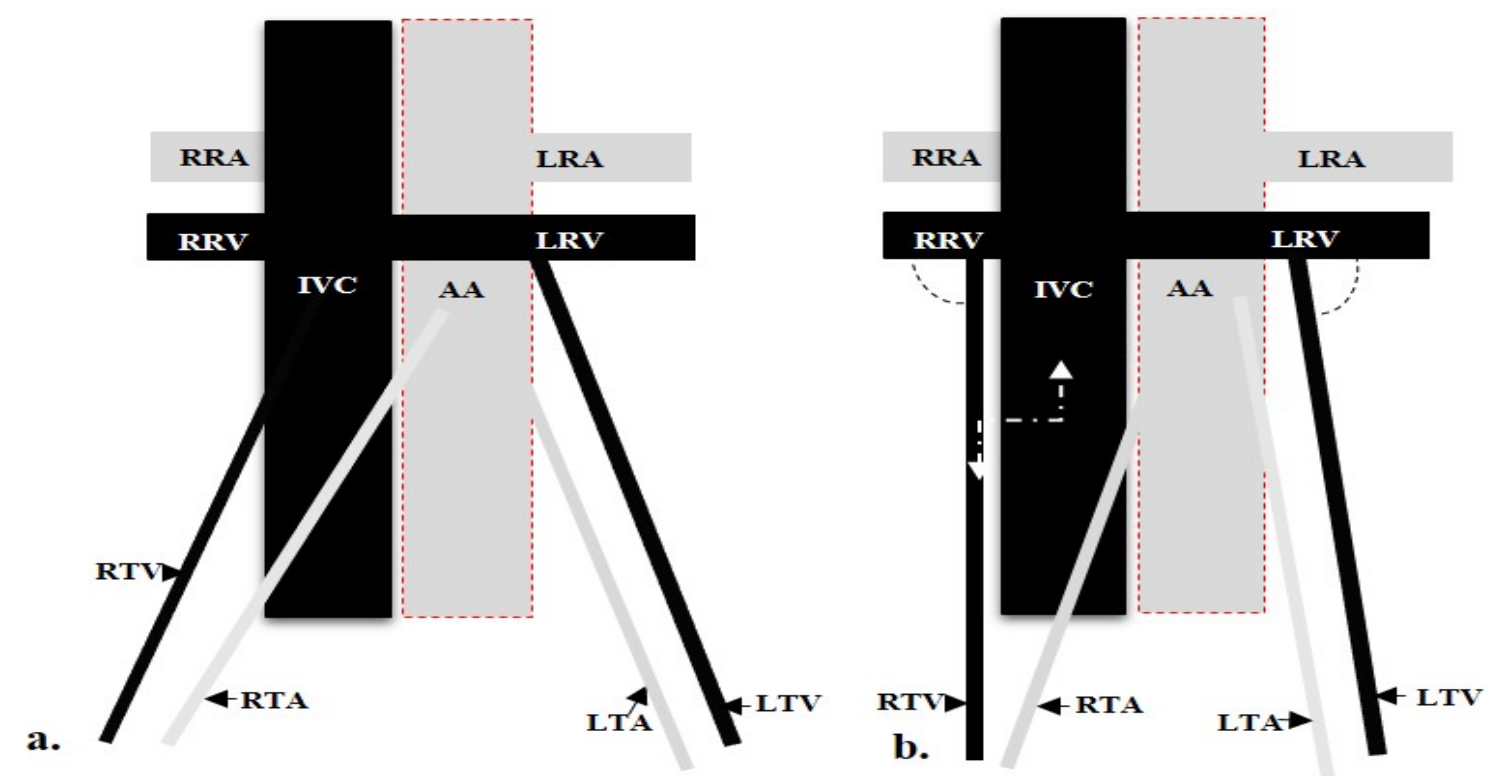

Figure 1. Drainage of the testicular vessels. a. diagram of normal drainage of the right testicular vein (RTV) to the IVC b. diagram of right testicular vein (RTV) drainage to the right renal vein (RRV) (in this case) with a $90^{\circ}$ angle and vertical course. (AA: Abdominal Aorta; IVC: Inferior Vena Cava; RTA: Right Testicular Artery; RTV: Right Testicular Vein; LTA: Left Testicular Artery; LTV: Left Testicular Vein; RRA: Right Renal Artery; RRV: Right Renal Vein; LRA: Left Renal Artery; LRV: Left Renal Vein)

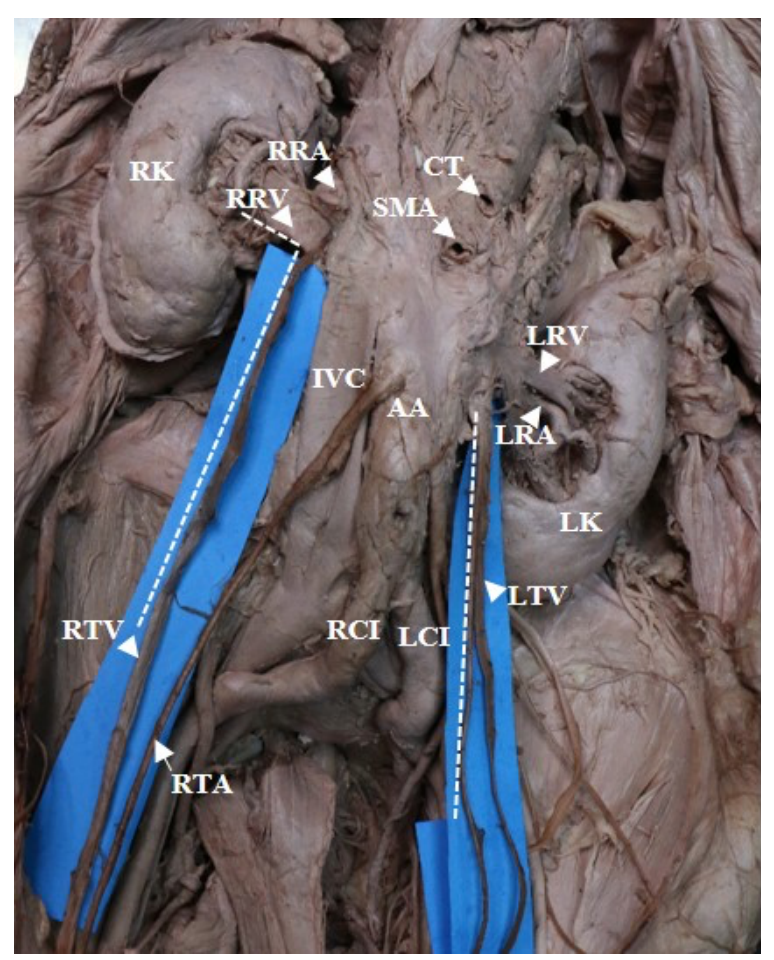

Figure 2. Unusual drainage variation of the right testicular vein (RTV). The right testicular vein (RTV) draining into the right renal vein (RRV) rather than to the IVC. (CT: Coeliac Trunk; SMA: Superior Mesenteric Artery; AA: Abdominal Aorta; IVC: Inferior Vena Cava; RTA: Right Testicular Artery; RTV: Right Testicular Vein; LTA: Left Testicular Artery; LTV: Left Testicular Vein; LK: Left Kidney; RK: Right Kidney) drainage patterns of testicular veins were classified according to a classification system presented by Itoh et al. (2). The fixed cadaver was of a 62-years old man, who had died of myocardial infarction. It was noted that the RTV drained into the RRV (Type III: the gonadal veins drain into the right renal vein), while the LTV drained into the LRV (Type III). The variation of type III RTV are illustrated in Fig. 1. It was shown that the RTV drained into the RRV at a $90^{\circ}$ angle $0.4 \mathrm{~cm}$ from the IVC. However, the left TV drained into the left RV at a $62^{\circ}$ angle $5 \mathrm{~cm}$ from the IVC (Fig. 2). Furthermore, the LTV coursed obliquely upward and lateral to the left side of the aorta, and joined the LRV. The RTV coursed vertically $\left(90^{\circ}\right)$ upward and lay 0.4 $\mathrm{cm}$ to the right side of the IVC and drained into the RRV, conforming to Type III (Type III refers to testicular veins draining into the renal veins) (Fig. 2).

\section{DISCUSSION}

The right testicular vein (RTV) originates from the lower part of the right subcardinal vein, and the bifurcation of the right subcardinal vein forms the terminal bifurcation of the RTV. Furthermore, it drains into the supra-subcardinal anastomosis. The suprasubcardinal anastomosis and sub-cardinal veins unite to form the IVC. Thus, the RTV drains into the IVC on the right side (Type I). Supra-subcardinal anastomosis also forms a part of the LRV; therefore, 
the LTV drains into the LRV. Nikolay et al. (4) described the lateral, middle, and medial divisions of the RTV. Moreover, they stated that the right lateral RTV drained into the RRV (type III); the intermediate and medial RTV drained at an angle between the IVC and the RRV (type II, referring to the gonadal veins draining into the junction of the IVC with the renal vein). However, the medial and lateral divisions of the LTV drained into the LRV (5). Das et al. (6) stated that the RTV drained into the right renal vein (RRV) (type III) in one cadaver out of $42(2.4 \%)$. Type IV refers to the gonadal vein draining into the IVC cranial to the renal vein or other veins (2) Itoh et al. asserted that $60 \%$ of RTVs drained into the right IVC caudal to the $\mathrm{RV}$ and were categorized as Type I. Furthermore, they claimed that $15 \%$ of RTVs drained into the RRV (Type III), while approximately $40 \%$ of LTVs drained into the LRV. Gupta et al. (7) reported that RTV terminated into IVC in $85 \%$, into RRV in $10 \%$ and into both in $5 \%$ cases. In $87.5 \%$ cases, the RTV drained in IVC at an acute angle, and in $12.5 \%$ cases, the angle of drainage in RRV was straight. In our study, type III venous drainage was recognized at a rate of $14.28 \%$. Asala et al. (8) reported the RTV ascended vertically and inserted into the RRV (Type III) rather than the IVC. Zini et al. (9) reported that the RTV might not usually drain by an oblique route to the IVC. Similarly, we report that the RTV drained into the RRV at a $90^{\circ}$ angle from the RRV, while the LTV climbed in an oblique way and drained into the LRV at a $62^{\circ}$ angle from the LRV. It can be said that drainage asymmetry could be significant in causing various pathologies, and variations of the drainage pattern could induce hemodynamic irregularities and lead to varicocele (2). Sadler (10) reported that the asymmetric drainage pattern of testicular veins was related to their embryological development and the variations from this typical drainage pattern can be traced to the embryological developmental process of the testicular veins. McClure et al. (11) asserted that the normal testicular veins, the renal veins and the segments of the IVC have a common origin from the subcardinal vein, and variation occurs due to the venous alteration of the anastomotic channel fetal subcardinal veins.

\section{CONCLUSION}

In conclusion, the abnormal and asymmetric drainage of type III right testicular veins in the retroperitoneal region might contribute to surgical invasive procedures with a proper diagnosis, accurate interpretation of images, and understanding of unusual right-sided varicocele conditions.

Acknowledgments: For access to cadavers, we are grateful to the Faculty of Medicine, Bahçeşehir University, Istanbul. The authors sincerely thank those who donated their bodies to science so that anatomical research could be performed. Results from such research can potentially increase mankind's overall knowledge that can then improve patient care. Therefore, these donors and their families deserve our highest gratitude.

Authors contributions: $\mathrm{BC}$ and $\mathrm{OE}$ contributed to the data analysis and manuscript writing. $\mathrm{BC}$ and $\mathrm{OE}$ conceived the project and contributed to final manuscript approval. All authors read and approved the final manuscript.

Conflict of Interest: The authors declare no competing interests. Peer-review: Externally peer-reviewed.

\section{REFERENCES}

1. Keith L, Moore R, Anne M, Arthur A, Dalley F. Clinically Oriented Anatomy. 8th ed. Baltimore: Lippincott Williams \& Wilkins, Wolters Kluwer Health; 2017.

2. Itoh M, Moriyama H, Tokunaga $\mathrm{Y}$, Miyamoto $\mathrm{K}$, Nagata W, Satriotomo I, et al. Embryological consideration of drainage of the left testicular vein into the ipsilateral renal vein: analysis of cases of a double inferior vena cava. Int. J. Androl. 2001;24(3):142-52.

3. Barut C, Ertilav H. Guidelines for standard photography in gross and clinical anatomy. Anat. Sci. Educ. 2011;4(6):348-56.

4. Nikolay $\mathrm{KH}$, Stilyanka DY. Variations of the bilateral testicular veins. J. Med. Biomed. Res. 2009;2(1):176-78.

5. Yang $\mathrm{C}-\mathrm{Y}$, Xue H-G, Tanuma K, Ozawa $\mathrm{H}$. Variations of the bilateral testicular veins: embryological and clinical considerations. Surg Radiol Anat. 2008;30(1):53-5.

6. Das S, Vasudeva N. Study of anomalous drainage pattern of right testicular vein. Nepal Med Coll J. 2005;7(1):21-2.

7. Gupta R, Gupta A, Aggarwal N. Variations of Gonadal Veins: Embryological Prospective and Clinical Significance. J. Clin. Diagnostic Res. 2015; 9(2): AC08-AC10.

8. Asala $S$, Chaudhary SC, Masumbuko-Kahamba $\mathrm{N}$, Bidmos M. Anatomical variations in the human testicular blood vessels. Ann Anat. 2001;183(6):545-9.

9. Zini A, Buckspan M, Berardinucci D, Jarvi K. Loss of left testicular volume in men with clinical left varicocele: correlation with grade of varicocele. Arch Androl. 1998;41(1):37-41. 
10. Sadler TW. Langman's Medical Embryology. 10th ed. Baltimore: Lippincott Williams \& Wilkins, Wolters Kluwer Health; 2006.

11. McClure CFW, Butler EG. The development of the vena cava inferior in man. Am.J. Anat. 1925;35(3):331-83. 